REVIEW

\title{
Nuclear Malaysia: Towards Being A Certification Body for Radiation Safety Auditors
}

\author{
Nik Arlina NIK ALI, Nurul Huda MUDRI and Noriah MOD ALI* \\ Innovation Management Centre, Malaysian Nuclear Agency, \\ Bangi 43000 Kajang, Selangor, Malaysia
}

\begin{abstract}
Current management practice demands that an organisation inculcate safety culture in preventing radiation hazard. Radiation safety audit is known as a step in ensuring radiation safety compliance at all times. The purpose of Radiation Safety Auditing is to ensure that the radiation safety protection system is implemented in accordance to Malaysia Atomic Energy Licensing Act 1984, or Act 304, and International Standards. Competent radiation safety auditors are the main element that contributes to the effectiveness of the audit. To realise this need, Innovation Management Centre (IMC) is now in progress to be a certification body for safety auditor in collaboration with Nuclear Malaysia Training Centre (NMTC). NMTC will offer Radiation Safety Management Auditor (RSMA) course, which provide in depth knowledge and understanding on requirement on radiation safety audit that comply with the ISO/IEC 17024 General Requirements for Bodies Operating Certification Systems of Persons. Candidates who pass the exam will be certified as Radiation Safety Management Auditor, whose competency will be evaluated every three years.
\end{abstract}

\section{KEYWORDS: Radiation Safety Audit, ISO/IEC 17024, Act 304, Radiation Safety Management Auditor}

\section{Introduction}

Current global market is very competitive and customers tend to choose the best products and services with high quality at economical cost. Standards ensure the desirable characteristics of the products and services such as quality, environmental friendliness, safety, reliability, efficiency and interchangeability, meet the customer's expectation. Conformity assessment or audit can be conducted by checking that products, materials, services, systems, processes or people measure up to the specifications of a relevant standard or specification. Today, many products require testing for conformity with specifications or compliance with safety, or other regulations before they can be put on many markets. International Organisation for Standardisation (ISO) guides and standards for conformity assessment represent an international consensus on best practices. Their use contributes to the consistency of conformity assessment worldwide and so facilitates trade.

Malaysian Nuclear Agency (Nuclear Malaysia) is a government agency whose responsibility is to introduce and promote the application of nuclear science and technology for national development. Nuclear Malaysia offers service and training on the application of nuclear technology, while maintaining research and development (R\&D) programme as the core business. Nuclear Malaysia is very concerned with quality in every product and service delivered to its customers. Innovation Management Centre (IMC), previously known as Quality Management Centre (QMC) is accountable to conduct and monitor all activities regarding

*Corresponding Author,E-mail:noriaha@nuclearmalaysia.gov.my (C) 2012 Atomic Energy Society of Japan, All Rights Reserved. quality and innovation in Nuclear Malaysia. The roles of IMC include registration for new application of certification, promoting awareness, training and consultation, conducting internal audit, arranging for external audit and also recertification every two years. Currently there are seven processes that have been successfully certified with ISO 9001:2008 whilst two laboratories achieved the ISO/IEC 17025 certification. For new certification, three processes are now in progress to obtain ISO/IEC 17020, ISO/IEC 27001 and cGMP certification by the end of 2011 .

\section{Requirement of ISO/IEC 17024}

International standard of ISO/IEC 17024 is a standard used to accredit certification bodies. This standard plays an important role to verify the competency of personnel worldwide thus increasing the mobility of the personnel with international standard. Via this certification, the skills of the personnel are standardised, consistent and can be trusted. In the United States, more than 1 million personnel have been accredited on their competencies via ISO/IEC 17024, in various background professions, including banking, medical, safety and finance.

ISO/IEC 17024 explains the guidelines for an organisation to recognise and certify personnel, and provides procedures on preparation, development and maintenance of certification scheme ${ }^{1)}$. It also highlights the essential requirements for the certification body to conduct well planned and structured examination. ISO/IEC 17024 focuses on competency verification to avoid bias and conflicts during the practice. It is different from the previous standard (EN 45013), where ISO/IEC 17025 clearly defined the 
knowledge, skills and ethics of the personnel. In general, the core elements needed in the verification of the competency of the personnel include the development of verified item, knowledge, skill and ethics of the personnel and validated examination system. In addition, the organisation conducting the examination must not be related directly to the certification body.

\section{Towards ISO/IEC 17024}

Recent management practice demands that an organisation inculcate safety culture in order to prevent hazard. For organisation that utilises radiation sources, radiation safety audit is the best practice to ensure that the safety of worker, public and environment are ensured at all times. Radiation safety audit involves contribution of all levels of staff and can be done either internally or externally. The effectiveness of radiation safety audit is largely depends on the competency of the auditor to confirm the safety level including preventive and corrective action taken by organisation. Thus, issues raised during safety audits present opportunities for improvements towards existing systems in each radiation facility.

Nuclear Malaysia has taken the initiative to introduce the ISO/IEC 17024 to verify the radiation safety auditor competencies. Radiation safety audit should be carried out properly and efficiently to improve the safety performance from good to excellent condition. The effectiveness of the audit depends entirely on the ability of the personnel responsible to carry out the radiation safety audits based on the radiation protection programme of the facility using the ionising radiation. This situation will lead to a culture of safety in the practice of radiation in the industries involved. Nuclear Malaysia's effort to gain the standard ISO / IEC 17024 for radiation safety auditor is the best way to strengthen the practice of radiation safety while creating a more inclusive culture on radiation safety in the country.

\section{Radiation Safety Auditor}

The target groups for the RSMA course are Radiation Protection Officers (RPO), Radiation Protection Supervisor (RPS), Safety Officers, radiation workers, radiologists, X-ray operators, supervisors, technologists, technicians, laboratory assistants, and those who are involved and interested in radiation safety management audit.

Among the requirements to be an auditor to radiation safety auditors, he or she must be employed within the radiation facility organisation as part of the quality assurance, or by third party inspectorates, inspection bodies, purchasers or consultants. Therefore, he or she should be able to prepare reports and make a responsible judgment. Moreover, the applicants should also be familiar with requirements of Act 304 , have working knowledge on radiation safety practices and radiation safety auditing.

This is in accordance with the responsibilities of the radiation safety auditor to conduct his/her radiation safety audit (self regulation) and to help promote radiation safety culture at the workplace.

\section{Certification Process}

In an effort for Nuclear Malaysia to obtain the ISO/ IEC 17024 certification, appropriate procedures and methods to validate competency of auditors to conduct audits based on the requirements of relevant acts and standards have to be designed. Procedures and methods developed will be certified by the relevant enforcement bodies, such as of the Atomic Energy Licensing Board, Ministry of Health Malaysia and Department of Standards Malaysia. Figure 1 shows the process of Radiation Safety Auditor certification.

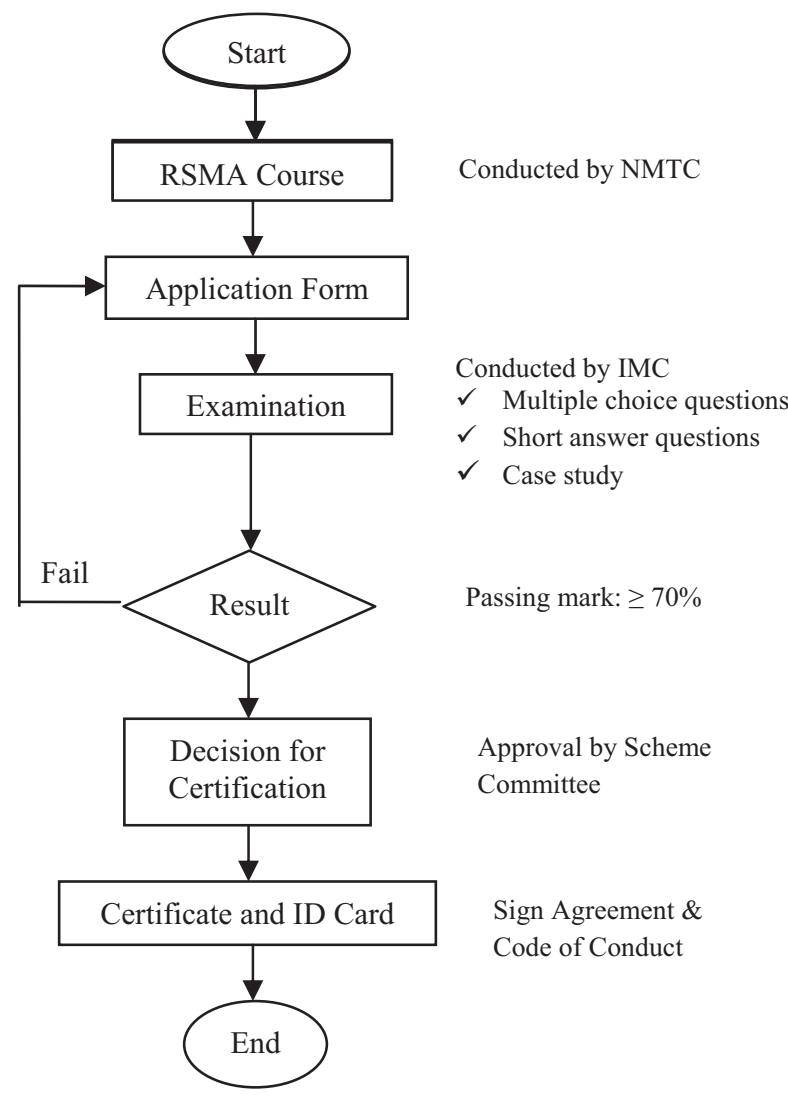

Fig 1 Process of Radiation Safety Auditor certification.

\section{RSMA Course}

Radiation Safety Management Audit Course (RSMA) will be managed by Nuclear Malaysia Training Centre (NMTC), which enables radiation safety auditors to gain exposure to the theory of radiation safety requirements and methods of radiation safety programme audits. The RSMA course will provide radiation safety auditor a certification that will be recognised by certification bodies, inspection bodies and authorities in Malaysia and internationally. The certification scheme is transparent, uniform and equitable, where the competency of the radiation safety auditor are verified through examination based on national and international standards. The teaching staff comprises of those with experience in radiation-related fields. This course is in preparation for the examination to be conducted by the examination unit of the IMC.

In general, through the RSMA course, radiation safety auditors will be provided with knowledge on radiation safety, related acts and laws on the radiation and on audit 
management system ${ }^{2}$. The RSMA syllabus for in the course is shown in Table 1.

Table 1 Syllabus of the RSMA course.

\begin{tabular}{|c|c|}
\hline Topic & $\begin{array}{c}\text { Duration } \\
\text { (hours) }\end{array}$ \\
\hline $\begin{array}{l}\text { Topic 1: Overview of Radiation Safety } \\
\text { (Fundamentals) } \\
\text { - Basic information on ionising radiation } \\
\text { - Effects of radiation to human } \\
\text { - Principle of radiation protection } \\
\text { - Radiological monitoring }\end{array}$ & 3 \\
\hline $\begin{array}{l}\text { Topic 2: Radiation Safety : Lessons Learnt } \\
\text { - Nuclear gauging } \\
\text { - Irradiation apparatus } \\
\text { - Unsealed sources } \\
\text { - Research } \\
\text { - NORM/TENORM } \\
\text { - Medical }\end{array}$ & 3 \\
\hline $\begin{array}{l}\text { Topic 3: Overview on Atomic Energy } \\
\text { Licensing Act, Act } 304\end{array}$ & 3 \\
\hline $\begin{array}{l}\text { Topic 4: Overview on Occupational Safety } \\
\text { and Health, Act514 }\end{array}$ & 2 \\
\hline $\begin{array}{l}\text { Topic 5: Requirements on Radiation Safety } \\
\text { Management System (RSMS) }\end{array}$ & 2 \\
\hline Topic 6: Fundamentals of Audit & 1 \\
\hline Topic 7: Auditor - Competency & 1 \\
\hline $\begin{array}{l}\text { Topic 8: Steps in Auditing } \\
\text { - Theory (preparation of audit plan, } \\
\text { conducting audit, opening and closing) } \\
\text { - Exercise (on given scenario) } \\
\text { - Presentation }\end{array}$ & 3 \\
\hline $\begin{array}{l}\text { Topic 9: Preparation of Checklist } \\
\text { - Theory } \\
\text { - Exercise (on given scenario) } \\
\text { - Presentation }\end{array}$ & 3 \\
\hline $\begin{array}{l}\text { Topic } 10 \text { : NCR Writing } \\
\text { - Theory } \\
\text { - Exercise } \\
\text { - Presentation (on given scenario) }\end{array}$ & 3 \\
\hline $\begin{array}{l}\text { Topic 11: Preparation of Radiation Safety } \\
\text { Audit Report } \\
\text { - Case Study } \\
\text { - Presentation }\end{array}$ & 4 \\
\hline
\end{tabular}

\section{Maintenance of Certification}

To ensure the competency and credibility of the certified radiation safety auditors, the certificates obtained should be renewed every three years and the auditors will be annually assessed through the surveillance process.

During the annual surveillance process, the radiation safety auditor must submit the following:

- evidence of examination on skill and competency

- evidence of current knowledge-based competency

- confirmation that the Code of Conduct has been adhered to and any complaints against performance has been resolved

- Audit report

This will be evaluated by the panel of assessors appointed and approved by the Scheme Committee. For the process of re-certification, radiation safety auditors will be evaluated based on the performance of three years. If the auditor does not fulfil the requirement, the certification will be suspended.

\section{Conclusion}

Nuclear Malaysia's effort to be recognised as a certification body is one of its commitment to promote radiation safety culture, including to explore new ways to enhance the profession of radiation safety auditors in Malaysia. Through this certification, the safety in radiation related fields will be assured to be in compliance at all times.

\section{Acknowledgment}

The authors would like to thank all research officers from Malaysian Nuclear Agency for their contributions and supports especially during the preparation of RSMA syllabus.

\section{References}

1) Laws of Malaysia Act 304, Atomic Energy Licensing Act 1984.

2) Malaysia Standard, MS ISO/IEC 17024: 2003, Conformity Assessment-General Requirements for Bodies Operating Certification of Persons, Department of Standard Malaysia, 2003. 